\title{
Human behavior in digital economy
}

\author{
The main trends
}

\author{
Seliverstova Nataliya \\ Institute of management, economic and finance \\ Kazan Federal University \\ Kazan, Russia \\ nat-grig17@yandex.ru
}

\author{
Iakovleva Elena \\ Department of Economics \\ Kazan Innovation University named after V.G. Timiryasov \\ Kazan, Russia \\ mifoigra@yandex.ru
}

\author{
Grigoryeva Olga \\ Department of Psychology \\ Kazan Innovation University named after V.G. Timiryasov \\ Kazan, Russia \\ g-pf@yandex.ru
}

\begin{abstract}
The aim of the work is to identify the trends of human behavior determined by the development of digital technologies. It has been shown that the features of human psyche, related to a new form of identity - digital nomad's way of life - are a barrier which does not allow technological progress to transform into rapid economic growth. Nevertheless, the conducted study has led to a conclusion that the development of the so-called digital economy should be seen as a large-scale social engineering. This requires a personality to possess focused attention, rationalization of actions, and logical sequence in actions. When launching a comprehensive socio-cultural process, one must not ignore the negative factors of the digital nomad's way of life, but take into account various risks connected with it, which will increase the efficiency of various IT projects implementation. It is essential to realize that the so called digital economy development should be perceived as a large-scale social engineering. And it is important to create conditions for transformation the benefits of the digital economy to economic growth.
\end{abstract}

Keywords - digital economy, digital nomad, upgrades, Internet, networks, behavioral barriers, economic growth, economic relations.

\section{INTRODUCTION}

Today, a systemic program is being launched in Russia, which is aimed at developing the economy of the new technological generation, the so called digital economy [1]. Digitalization of economy is going on intensively all over the world, leading to essential changes in all spheres of the human activity $[2 ; 3 ; 4]$, changing approaches to working with data [5], and changing the human behavior. According to the World Bank statistics, for instance, every 10 additional mobile phones (per 100 people) on average result in about $0.8 \%$ of the GDP growth in developing countries [6]. Undoubtedly, by reducing transactional costs and saving other kinds of resources (in particular, human resources), the spreading of automation means has a positive impact on the economy dynamics (currently the authors are not considering the social aspect, though it is well known that the economy informatization leads, other things being equal, to unemployment growth among the low-qualified and, partially, middle-qualified personnel).

Social networks and messengers as communication technologies have become customary [7]. It is hard to imagine a modern office or production premises without new technologies of production: digital devices and the Internet, which have led to the drastic changes in the earlier business processes. According to the modern trends, the share of digital trade in the total volume of commodity turnover is forecasted to grow from $7.4 \%$ in 2015 to $14.6 \%$ in 2020 [8]. This implies accepting the new technologies of exchange and distribution by more and more people.

It is believed that currently people are entering a golden age of information technology; this technological wave is in the maturity stage in its life cycle of development and this implies the ubiquity of automated control systems and digital technologies.

The Chairman of the Board of the Eurasian Economic Commission T. Sargsyan [9] notes that the assets in traditional economic sectors, which have not been digitized, are dramatically devalued compared to the value growth of the new digital assets. The leading experts agree that in the nearest 15-20 years the world will face the ubiquitous implementation of the platform business model and, actually, the reformatting of the habitual organizational structures of industry and trade. These changes in technology lead to transformation of the human behavior and to altering the prevalent behavioral and cultural patterns, which influences all spheres of human activity. Till now, these changes have been studied little by the scholars. The knowledge of these trends will reduce the level of uncertainty for economic agents, create the basis for further research, including in the sphere of increasing the efficiency 
of elaborating and promoting the domestic solutions in the field of information system and technologies.

The modern scholars (D. Bell [10], J. Baudrillard [11], M. Castells [12]) determined that since the end of the 1990-s the developed industrial states completed the fundamental modernization processes and transited to the new level of socio-cultural changes, which was called the "informational society". However, not all researchers agree with this viewpoint (A. Giddence [13], J. Habermas [14]), as they believe that the growth of informational streams in modern societies does not change a person, a culture, or a social media, but merely characterize the speed of changing the social processes [15].

High technology and the information explosion has transformed social space. Modern man can not imagine his life without the specific set of electronic devices. It is no coincidence that some scientists use the scientific concepts such as "technological man" and they sometimes name the new generation metaphorically as "generation head down".

Under modern conditions, when the external and internal factors in the Russian economy form another round of interest in producing and developing the domestic software and databases, the Russian-made platform solutions and solutions in the sphere of enterprise management information systems gain more and more popularity. Taking into account that at present there is a certain basis of theoretical elaborations about the process of creation and developing of various classes of software, the problems of practical implementation of the process of information technologies development become more and more behavioral in character, which determines the topicality of the present research.

\section{RESULTS}

Some researchers think that a modern human being can be characterized as a digital nomad [16]. The main attributes of life are the network and access to it, as well as a set of various electronic devices, mobile telephones, plastic cards, without which life is practically impossible.

The habitual pattern of life of a modern person is their inclusion into the virtual space. The thing is that virtuality appears to be quite a self-sufficient and even comfortable space, rendering a lot of conveniences to a person. Constantly living in the digital world, a nomad performs their labor activity, communicates with their kin, spends their free time and gets information. The reality itself is perceived nowadays via the digital world, and the contact with it appears to be mediated.

The above enables to speak of the new type of dependence - the electronic one. However, it is not fully realized by an individual, because the largest part of wakeful time is connected with it, being perceived as a norm.

A modern nomad shows many features similar to those of ancient nomads. They strive for subjugation of both real and virtual spaces, constantly finding new adventures in them. In turn, the adventures become an impulse for further search. Unfortunately, a modern nomad is not tied to anything: they do not have a fulcrum embodied in Motherland, home, key values and stable predilections. Mobility of electronic devices directly influences the nomadic way of life, in which everything appears to be mobile and fluid. Remember the characteristics of modernity given by Z. Bauman: "liquid". It is characterized by high speed of changes in the social sphere, in particular - the trends and information, which leads to the freedom of movement, elusiveness and disconnection of people.

Technologies like the Internet have essentially changed human behavior. Of the scale of operations and transactions committed via the modern communication applications, speaks the mere fact that 50 bln messages are sent daily through WhatsApp application only.

The Google search engine processes 59141 search enquiries in one second, which makes more than 5.1 bln enquiries a day [17], - an impressive amount.

So these are a huge movement digital flows; modern reality is supplemented by virtual; people really are building the digital economy.

Transience, mosaicity and antinomic character of information field in the electronic world influences the apprehension abilities of a human. As a rule, the knowledge appears to be shallow and is soon forgotten, the thoughts lack accuracy and logical sequence, which is reflected in deeds and actions. The change of information streams, forcing to constantly switch attention, leads to distracted perception and defects in memorizing [18]. The problem is that the extracted information is not carefully read, analyzed and compared. As a rule, it arises for a certain reason, is quickly reproduced and instantly disappears from memory.

Today, only $13 \%$ of the Internet users receive no newsletters [24], while the majority of users are subscribed to updates of various global information streams, such as news sites and other similar resources in the Internet.

$34 \%$ of users delete uninteresting newsletters without even opening them (figure 1). But what may appear more important $-14 \%$ of respondents keep opening and reading uninteresting news and subscriptions (figure 1), i.e. increase the informational noise and informational trash, in which they exist.

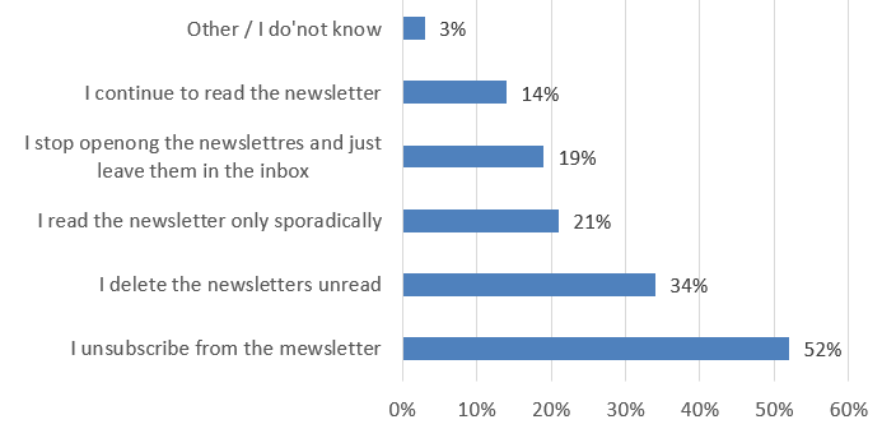

Fig 1. Dealing with newsletters that are no longer interesting, in percent, 2017.

Trajectory of a modern nomad is unpredictable: even if the starting and finishing points are marked, the route between 
them appears to be twisting, which demonstrates the dominance of the irrational and emotional over the rational. It is these qualities that make the nomad feel excitement and passion for life, which temporally substitute the crisis character of the modern nomad's existence. There are a lot of factors influencing the anthropological crisis, and one of them is the new form of identification, connected with the nomadic way of life.

A modern nomad, initially charmed by unlimited freedom, gradually becomes burdened with it. They become tragically aware that "nobody has their own definite sphere of existence, nothing is supported by good habits, nothing has rules; there is not even a hearth; there is nothing attaching, arousing sympathy or love, nothing solid, nothing constant; everything elapses, everything flows, leaving no trace outside or inside you" [19]. Skimming over information pages without stopping to think about the meaning of life, a nomad often appears to be helpless in situations demanding serious approach and deep knowledge.

One of the problems of an electronic nomad is total solitude. Living within the information buzz and constantly communicating in the virtual world, a nomad, nevertheless, surrounds oneself with simulations (including those related to friendship and love), which are not able to substitute real life and meeting people.

Figure 2 below shows the number of active users ( $\mathrm{mln}$ people) of the largest social networks and messengers as for March 2017 [20] (Figure 2).

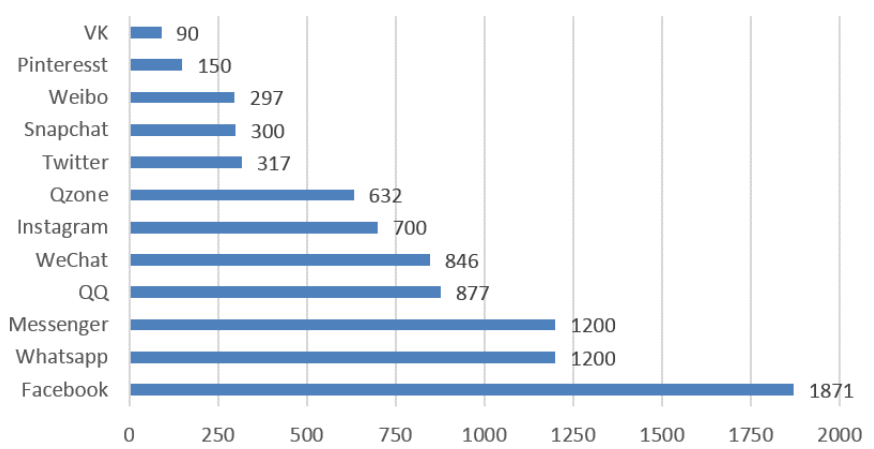

Fig 2. The number of active users (mln people) of the largest social networks and messengers, 2017.

A user was recognized as active if they visited the systems at least a month ago. Totally, these are billions of people, and many of them use more than one network. In spite of the alienation of contacts in networks, these are nevertheless performed "by means which had been impossible before, as they carry devices possessing the possibilities of both a communicator and a computer" [21].

Applications that have communication capabilities are most popular among Internet users. Social apps are the most popular among all categories of downloaded applications (figure 3 ). And this is an important trend. People would like to communicate. Homosapience is a bio-social creature, and communications with each other is an important part of personality. Just now in connection with change of leading technology, communication is transformed.

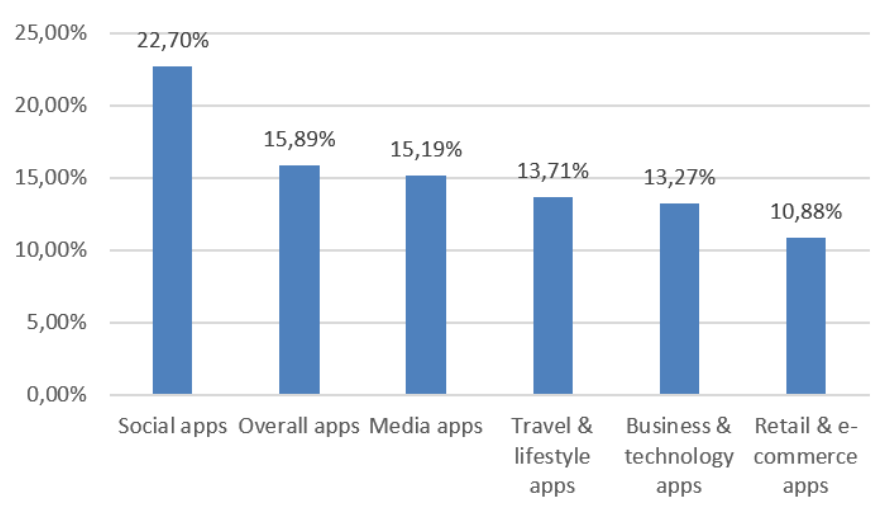

Fig 3. Number of times an average application from the categories is launched per month, Q1, 2017.

Communication takes on the new channels and opportunities. Communication through smartphones, tablets and other electronic devices will continue to increase in percentage figures, because now even business communications are increasingly moving into the digital plane.

The majority of smartphone users $(77 \%)$ spend most of their time on only 3 of their most used applications (figure 4) according to the results of a survey of U.S. smartphone users $18+$ on June 2017 (source: comSource). One also can find the data which show that average \# of apps used per month by each user is 25 . It is quite a lot. And these data are interesting.

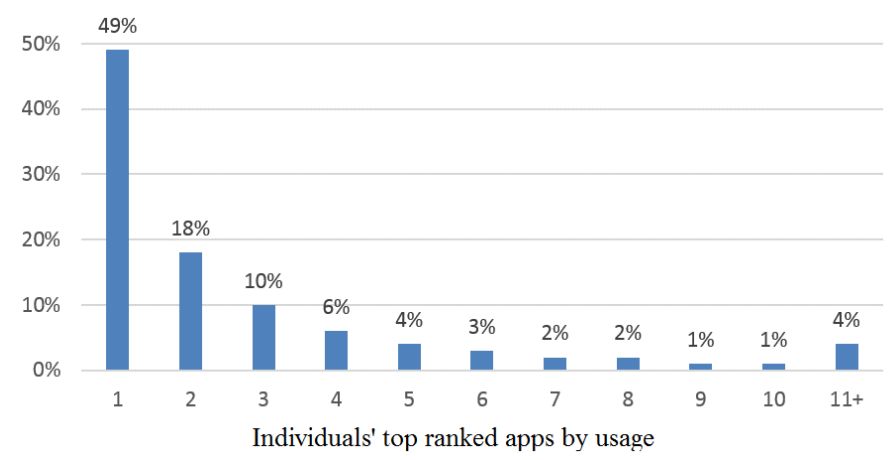

Fig 4. Individuals' top ranked apps by usage, U.S. smartphone users, June, 2017.

Probably, this behavior is typical for Internet users not only in USA but also in other countries of the world. Although people have reliable data. In the future may be interesting the cross-country comparison of statistics of use of various applications on electronic devices by users from different regions of the world. One can assume the behaviors of a Internet users is depend on prevailing cultural norms and preferences. Probably cultural factors have a significant role on the behavior of different groups of people in the digital economy. And it can be an interesting subject for further research.

Currently people do not have sufficient sources of such information, because the experience of collecting and processing these statistics is still not sufficient. Nevertheless, if such information was collected and it could be obtain - this 
data would be interesting. In addition, their dynamics may be could show the relationship of the development of information technology and economic growth from social and cultural factors as well as from geopolitical events.

Nevertheless, the electronic nomadic way of life has its advantages, too. It is characterized by high mobility, being able to quickly transform and meet the demand of the time. An electronic nomad has a choice within the great variety of the modern world. The dynamic character of the network removes the necessity of personal presence in many situations, which speeds up the processes and saves personal time.

A modern nomad appears to be "a child of commerce", while the wi-fi wireless networks effectively communicate the users to such services as transport schedules, availability of theatre tickets and parking places [21]. More and more often today, many kinds of activity, in particular, advertisement, trade, communication, are performed via electronic means. This is often associated with hasty purchases and excess demand stimulation. That is why a number of researchers, like Bigné-Alcañiz E. [25], Stenger T. [26], Cheung C. [27], Begalli D. [28] dedicate their works to the study of consumer behavior in the Internet.

Electronic nomads are a constantly enlarging mass. While the elder generation often unwillingly yields to the modern format of life, the new generation of children joins the crowd of modern nomads actually from birth.

Modern generation is surrounded by electronic devices, and they do not perceive the information environment as something alien or external to them. For them it is natural habitat, they become accustomed to it since the first years of their life. Generation 2000-years is a generation named "Z", has specific features. Scientists of different disciplines are already study patterns of Z-generation behavior (especially in labour relations within organizations - on this subject there are a lot of papers).

Meanwhile, the nomadic way of life entails not only advantages but also certain dangers and risks. The electronic world allows propagation of simulations leading to various ambiguities and misunderstanding, which impedes the process of communication, business cooperation, etc. Hence, it bars economic growth and development and further increasing the wellbeing of economic agents.

Moreover, virtuality creates illusion of real life, thus blurring the boundaries between them. For the most part, this world is anonymous, which implies alienated communication. Anonymity leads to the permissiveness, connected with violation of boundaries/rules/laws, and to the low threshold of personal responsibility. The lack of the core and affections in life, constant roaming in the networks, form the state of nonattachment in existence, which aggravates the existential fears.

\section{DISCUSSIONS}

One cannot but notice that the Internet has become the medium for information exchange, the medium surrounding us actually everywhere on Earth. This essentially changes people's idea of distances and probability/improbability of certain events.

Information technologies can help to develop cooperation between the regions, preventing the isolation of the constituent entities and promoting the strengthening of the domestic market and formation of the common economic space [29]. It is very important to countries with large territory, for example as Russian Federation.

News is now spreading faster than a news release is broadcasted, and all the more faster than a periodical is published.

According to the founder of Amazon, Jeff Bezos, if one makes one's customer unhappy in the physical world, the customer will tell about it to one's 6 friends, but if one makes the customer unhappy in the Internet, the customer can tell 6000 friends about it. Today, everybody has to take this into account the issues of customers' loyalty management, which are now much more significant than before due to the development of new means and tools of digital communications.

This influences people's life, the actions people perform every day when at work or making purchases [30]. People's behavior as economic agents has changed too, which creates new challenges for economy and for enterprises nowadays.

At the same time, the features of human psyche do not allow us to transform this technological progress into the equally rapid economic growth. An electronic nomad just cannot constructively perceive, including due to cognitive features, an essential part of these technological possibilities. People dissipate their intellectual efforts for the increased volume of information and start consuming excessively - the so called "information noise".

The described phenomena are behavioral barriers for the development of informational technologies in the aspect of their application to achieving economic objectives.

The barriers in cultural field require deep consideration and study, as they are non-material, notional objects, related to the historical features of development of a particular territory and the established customs of business intercourse. At the same time, it is these barriers - in the form of weak individual culture - may appear to be an insurmountable obstacle in the way of mass technological transformation of economy.

Pierre Bourdieu even speaks of the possibility to define a "cultural capital". By analogy of a human capital, he interprets cultural capital as "the advantages transferred by the elites to their children (skills of oral and written speech, aesthetic values, ability to interact with people, orientation towards success) and increasing the possibilities for their social mobility" [22]. Essentially, this is the collective unconscious of the nation.

One of the most delicate mechanisms, determining the activity of a human being oriented towards the human standards of one's deeds, the quality of one's interaction with the others, is ethics. Ethics serves as a regulator of human behavior and interpersonal relations. According to M. Rykhtik [23], close attention should be paid to the study of values and 
ideals which will determine the content of the "new" civilization appearing on the basis of new technologies.

In particular, an example of the increased attention to ethical issues is the development of bioethics, which is a spectacular event not only in the history of science but also in the history of society and state. In 1997, the European Council adopted the Convention on Bioethics, joined by the majority of European states. The leading experts in bioethics believe that its development as a social institution has been manifested in creating a system of committees on ethics, both in the healthcare system and in scientific-research and educational institutions. This has become possible due to the awareness of the fact that the development of biomedical technologies not only promotes healthcare but also bears new risks. The created committees on ethics have become not only a social mechanism for the human life protection but also a subject of innovative activity management. In Russia, people are just at the beginning of this path, which, for example, in the USA took almost 10 years. After prolonged debates in the 1960-s, the US Congress elaborated the principles of GCP - Good Clinical Practice, ensuring the strict scientific control over creation of new medications. Thus, GCP is to create conditions for developing and marketing of the safe and efficient medications [23].

In this respect, it is essential to realize that the so called digital economy development should be perceived as a largescale social engineering. In this case, the issue of popularization of further informatization at modern enterprises is not only an economic but also a socio-cultural task, implying working with the existing cultural barriers for their gradual elimination.

It is important to create conditions for transformation of the digital economy to economic growth and increased productivity. Government should encourage the automation of production where added value is created. It is important to develop the activities of these subsidiaries so that the labor force freed up by automating found employment at the same enterprise or other organizations, but would not have been beyond the economic life. This is an important social moment, but its underestimation will be a drag on economic development.

It is essential to launch the comprehensive socio-cultural process, in which the managerial and technological solutions are subject to humanitarian goals, while the humanitarian goals are sufficiently coordinated with the economic objectives.

\section{CONCLUSIONS}

The paper identified and described main trends in human behavior. According to analysis of a large number of literary sources, one can conclude that the digital economy affects the thinking and behavior of a person.

In the human behavior can be highlighted the following modern trends:

- high speed shift in the all social processes - especially among trends and information;
- the antinomy of the information sphere in the electronic world, which affects to the person' thinking abilities;

- uncertain sequence of actions and judgments in connection with the surface knowledge;

- Internet users download the most applications with communication capabilities;

- tendency to break boundaries, rules and laws in the result of the increased anonymity action in the Internet;

- people are now more mobile, so loyalty management are now much more significant than before, due to the development of new means and tools of digital communications.

Furthermore, this research indicated that there is a bilateral causality between information technologies and human behavior. Therefore, it can be inferred that information technologies has a positive effect on economic and business activities, but also has some negative effects to patterns of human behavior.

\section{References}

[1] Program "Digital economy of the Russian Federation", adopted by the Decree of the Russian Federation government of 28 July 2017 no. 1632p.

[2] K.Kushida, J.Murray and J.Zysman, "Diffusing the Cloud: Cloud Computing and Implications for Public Policy", Journal of Industry, Competition and Trade. 209, 2011.

[3] M.Kenney and B. Pon, "Structuring the Smartphone Industry: Is the Mobile Internet OS Platform the Key?", Journal of Industry, Competition and Trade 239, 2011.

[4] J.Rifkin, "The Third Industrial Revolution: How Lateral Power is Transforming Energy, the Economy, and the World", New York Times. 2011. ISBN 978-0-230-11521-7.

[5] A.Hearn (2014), «Sir Tim Berners-Lee speaks out on data ownership», The Guardian, 8 October 2014.

[6] The New Digital Economy. How it will transform business, Oxford Economics. A research paper produced in collaboration with AT\&T, Cisco, Citi, PwC \& SAP. 2011.

[7] N.J.Hancock, N.R.de Joux, S.C.Wingreen, S.Kemp, J.Thomas and W.S.Helton, "Positive post-disaster images: A daydream machine?", British Journal of Psycholog, Vol. 108, Issue 3, pp. 528-543 y, 2017.

[8] Digital Economy Compass, 2017. URL: www.statista.com.

[9] T. Sargsyan, "Digital no-alternativeness", Works of Free Economic Society of Russia, Vol. 204, pp.67-72, 2017.

[10] D.Bell, "The coming of post-industrial society: A venture of social forecasting”, N.Y.: Basic Books, 1973.

[11] J. Baudrillard, "Consumer society. Its myths and structures", translation from French, afterword and comment by E.A. Samarskaya.Moscow: Kulturnaya revolutsiya Publ., 2006, 269 p.

[12] M.Castells, "The Rise of the Network Society", Of The Information Age: Economy, Society and Culture. Oxford: Blackwell, Vol. 1, pp. 437-464, 1996.

[13] A.Giddens, "Modernity and self-identity", Stanford: Stanford Univ. Press, 1991, 256 p.

[14] J. Habermas, "Structural change of public sphere: research on the category of bourgeois society.Moscow: Ves Mir Publ., 2016.

[15] L. Pshenichnikova, "Evolution of the modernization concepts: sociocultural aspects", Bulletin of Chelyabinsk State University, Vol.17(346), Issue 33, pp. 47-50, 2014. 
[16] N.Grigoryeva, E.Yakovleva and O.Grigoryeva, "Opportunistic Behavior as Behavior Manipulations", American Journal of Applied Sciences, 13 (9), pp. 996-1005, 2016.

[17] Internet Live Stats, The official World Wide Web Anniversary Site. URL: www.internetlivestats.com.

[18] M.Mamardashvili, "Soznanie i tsivilizatsiya" [Consciousness and civilization], M.: Progress, 1990, pp. 107-121.

[19] P.Ya.Chaadaev, "Filosoficheskie pis'ma" [Philosophical letters], M.: Rimis, 2011.

[20] Digital Economy Compass, Statista.com. 2017, April. URL: https://www.statista.com/page/compass.

[21] S.Makkuayr, "Mediynyy gorod: media, arkhitektura i gorodskoe prostranstvo" [The media city: media, architecture and urban space], Mosscow: Strelka Press, 2014.

[22] P.Bourdieu, "Esquisse d'une théorie de la pratique, précédé de trois études d'ethnologie kabyle", Genève: Droz, 1972.

[23] M. Rykhtik, "Humanitarian aspects of modernization", Region under modernization: social institutions: works of the2nd International scietific-practical conference, 5 April 2013 - Nizhniy Novgorod: NISOTs Publ., 2013.

[24] Newsletter Advertising. Consumer Survey 2017 e-Commerce \& Retail, URL: www.statista.com.
[25] E.Bigné-Alcañiz, C.Ruiz-Mafé, J.Aldás-Manzano and S.Sanz-Blas, "Influence of online shopping information dependency and innovativeness on internet shopping adoption", Online Information Review, no. 32, pp. 648-667, 2008.

[26] T.Stenger, "Les Processus de Décision d'Achat de Vin par Internet: Entre Recherche d'Information et Prescription en Ligne", Décisions Marketing, no. 49, pp. 59-70, 2008.

[27] Cheung C., Zhu L., Kwong T., Chan G. and M.Limayem, "Online Consumer Behavior: A Review Agenda for Future Research”, 16th Bled eCommerce Conference eTransformation, Slovenia, 9-11 June 2003, pp. 194-218.

[28] D.Begalli, S.Codurri and D. Gaeta, "Wine and web marketing strategies: The case study of Italian speciality wineries", British Food Journal, no. 111, pp. 598-619, 2009.

[29] L.Gadelshina, R.Kundakchyan, T.Vakhitova and L.Zulfakarova, "Role of interregional cooperative relations of Russian constituent entities in strengthening the common economic space", Journal of Economics and Economic Education Research, Vol.17, Special Issue 1, 2016, pp. 59-67.

[30] T. Vakhitova and L. Gadelshina, "The role and importance of the study of economic subjects in the implementation of the educational potential of education", Procedia-Social and Behavioral Sciences Journal,The Proceedings of 6th World Conference on educational Sciences, 2014 Vol.191, 2 June 2015, pp. 2565-2567. 